\title{
A regional approach to climate adaptation in the Nile Basin
}

\author{
Michael B. Butts ${ }^{1}$, Carlo Buontempo ${ }^{2}$, Jens K. Lørup ${ }^{1}$, Karina Williams ${ }^{2}$, Camilla Mathison ${ }^{2}$, \\ Oluf Z. Jessen ${ }^{1}$, Niels D. Riegels ${ }^{1}$, Paul Glennie ${ }^{1}$, Carol McSweeney ${ }^{2}$ Mark Wilson $^{2}$, Richard Jones ${ }^{2}$, \\ and Abdulkarim H. Seid ${ }^{3}$ \\ ${ }^{1}$ DHI, Agern Alle 5, DK 2970, Hoersholm, Denmark \\ ${ }^{2}$ UK Met Office, FitzRoy Road, Exeter, Devon, EX1 3PB, UK \\ ${ }^{3}$ Nile Basin Initiative Secretariat (Nile-Sec), Plot 12 Mpigi Road, Entebbe, Uganda \\ Correspondence to: Michael B. Butts (mib@dhigroup.com) \\ Published: 17 October 2016
}

\begin{abstract}
The Nile Basin is one of the most important shared basins in Africa. Managing and developing the water resources within the basin must not only address different water uses but also the trade-off between developments upstream and water use downstream, often between different countries. Furthermore, decisionmakers in the region need to evaluate and implement climate adaptation measures.

Previous work has shown that the Nile flows can be highly sensitive to climate change and that there is considerable uncertainty in climate projections in the region with no clear consensus as to the direction of change. Modelling current and future changes in river runoff must address a number of challenges; including the large size of the basin, the relative scarcity of data, and the corresponding dramatic variety of climatic conditions and diversity in hydrological characteristics. In this paper, we present a methodology, to support climate adaptation on a regional scale, for assessing climate change impacts and adaptation potential for floods, droughts and water scarcity within the basin.
\end{abstract}

\section{Introduction}

The Nile River is the longest river in the world (UNEP, 2010) and the Nile Basin (Fig. 1) is one of the most critical and most important shared basins in Africa, hosting $25 \%$ of Africa's population (SEDAC, 2010) while accounting for only $10 \%$ of its landmass. Within the basin, agriculture, energy production and livelihoods all depend strongly on the flows. The region is facing rising levels of water scarcity, high population growth, watershed degradation and loss of environmental services (UNEP, 2010). In addition, the water resources are highly sensitive to climate change (Conway et al., 2007).

The Nile basin's climate varies significantly from extreme aridity in the north, including Egypt and Sudan, to the tropical rainforests in Central and East Africa and parts of Ethiopia. The distribution of precipitation can be categorised into two distinct regions; the Equatorial (or East African) lakes and the Ethiopian highlands (Fig. 1). There are significant differences in the wet and dry period distribution with some areas in the tropical region of the Nile basin having two rainfall seasons. In addition, there is significant interannual and inter-decadal variability, which also has important implications for the management of water resources in the Nile (Conway, 2005). In addition, many past studies have demonstrated that modelling current and future changes in river runoff presents a number of challenges: the large size of the basin, the relative scarcity of data, its geographical location and the corresponding dramatic variety of climatic conditions and diversity in hydrological characteristics. On top of these hydrological challenges, the climate projections are inherently uncertain because of the natural variability of the climate system, the uncertainty in future anthropogenic emissions and the uncertainty resulting from our incomplete understanding of how to represent important climate system processes in climate models (Buontempo et al., 2011). Nevertheless, decision-makers in the region need to evaluate and implement climate adaptation measures. Such climate adap- 

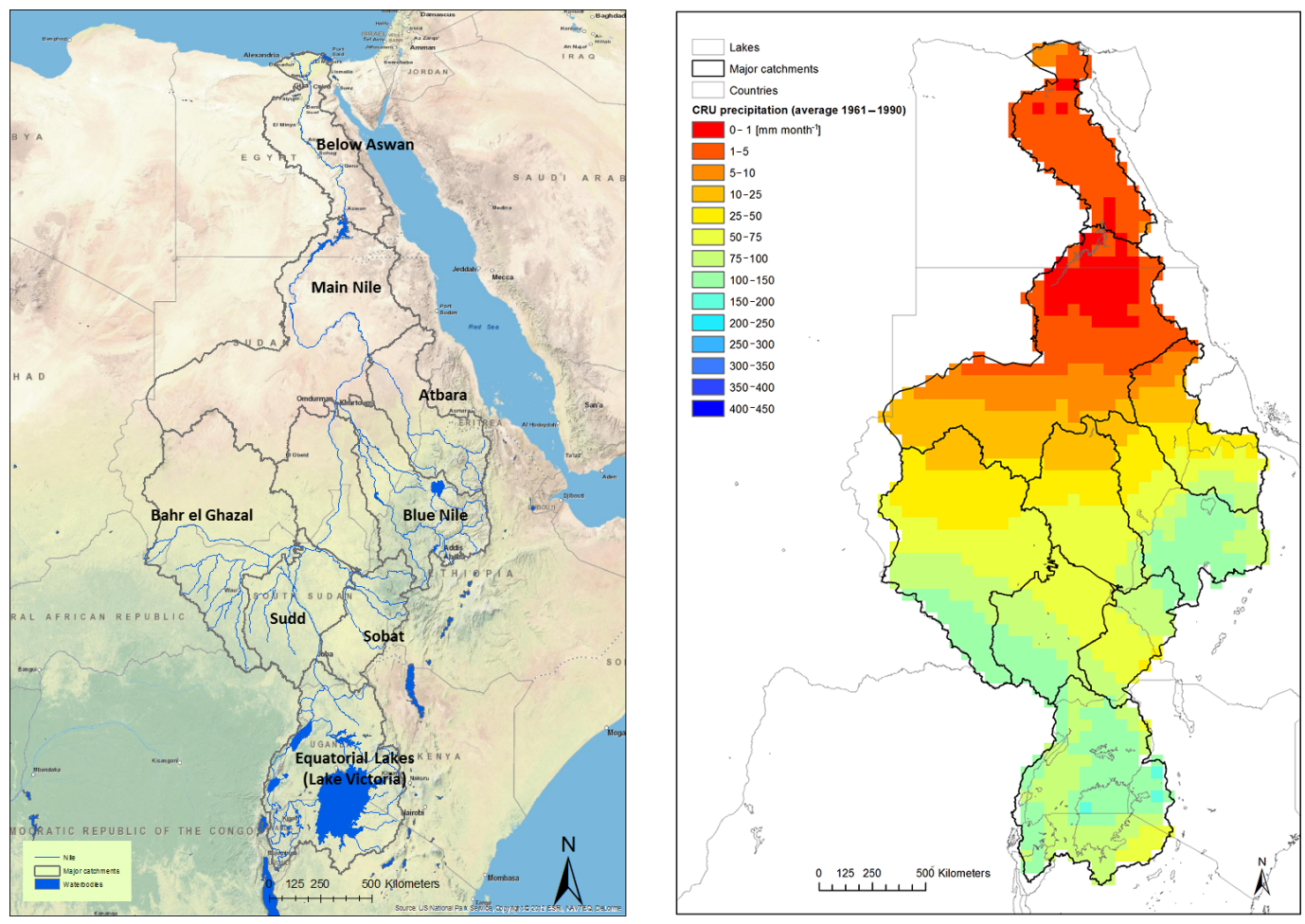

Figure 1. An overview of the Nile Basin (left) and distribution of annual average rainfall in $\mathrm{mm} / \mathrm{month}$ for the period 1961-1990 (right), from CRU (Harris et al., 2014).

tation measures can be implemented at the local, sub-basin or national scale. However, within trans-boundary basins like the Nile the implementation of such measures locally may have important impacts regionally particularly downstream of those measures. Therefore, tools and information are required to understand climate change and adaptation impacts at the regional scale.

\section{Regional climate modelling}

In this study, the Perturbed Physics Ensemble (PPE) approach is used. This PPE approach (Collins et al., 2006) represents the uncertainties or variability in climate projections by perturbing uncertain parameters to create new versions of the climate model. Each of these versions is characterised by different values for a set of parameters that describe the basic unresolved physical processes (Collins and Knight, 2007; Palmer and Williams, 2008). This approach was used to generate a large Global Climate Model (GCM) ensemble and here we apply a recently published systematic methodology (McSweeney et al., 2012) to select a subset of 5 GCM ensemble members. The selection is based on their ability to reproduce important features of the present-day climate over Africa while capturing the range of outcomes from the GCM ensemble (Buontempo et al., 2015). The ability of the selected ensemble to reproduce the rainfall patterns over Africa is illustrated in Fig. 2. To obtain high-resolution information suitable for assessing climate change impacts on flows in the Nile, these GCMs were dynamically downscaled, i.e. lateral boundary conditions from the GCMs are used to drive the regional climate model, HadRM3P, over the $50 \mathrm{~km}$ resolution Africa CORDEX (Giorgi et al., 2009) domain. Based on these new RCM simulations, change factors were derived for all 5 ensembles, for temperature, potential evapotranspiration and precipitation and for two periods 2020-2049 and 2070-2099.

\section{Regional hydrological modelling}

To represent the flows and water resources on the regional scale, both for climate change impact assessment and for climate adaptation scenarios, distributed hydrological modelling is required. In this study, a sub-basin based modelling approach using MIKE HYDRO (DHI, 2013) was adopted. The rainfall-runoff processes are represented using the NAM model (Butts et al., 2004, 2007). The runoff from the subbasins then becomes the inflow to the river or channel network representation used in MIKE HYDRO (Fig. 3). The MIKE HYDRO BASIN model represents rivers and their main tributaries as a network consisting of branches and calculation nodes. Branches represent the individual river sections, while the nodes represent either a confluence or a location where certain water activities occur. These include, for instance, multipurpose reservoirs, withdrawals for wa- 

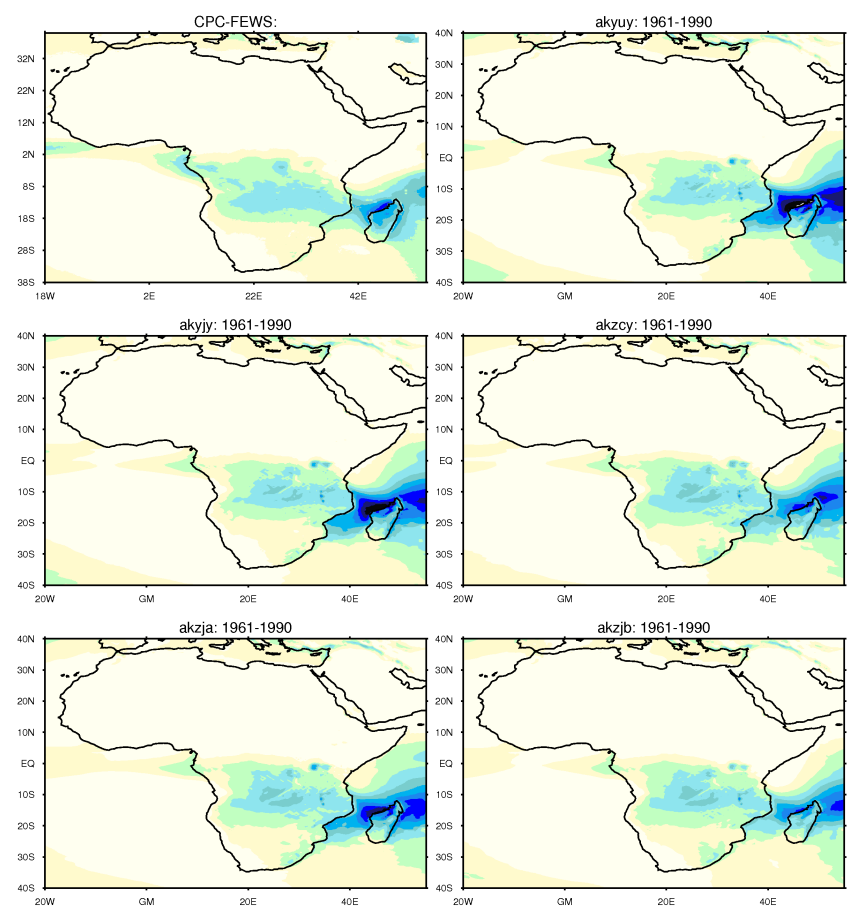

Figure 2. Comparison of the observed and simulated precipitation for Africa for the period June-September (JJAS). The observations are from CPC-FEWS (Love et al., 2004) cover the period 19832012 while the simulations cover the 1961-1990.

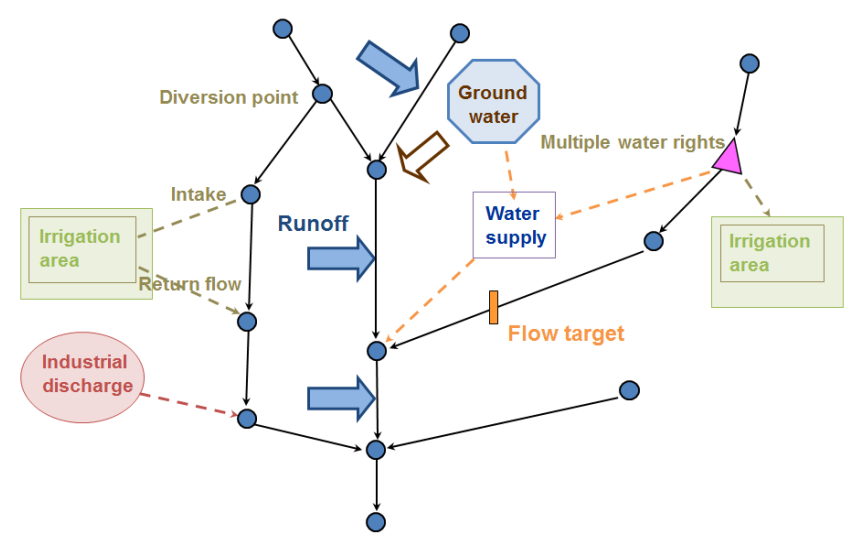

Figure 3. Schematic of the MIKE HYDRO network model including different water activities and water users.

ter supply or irrigation, effluent discharges, diversion canals and systems, gauging stations, low flow control points and priority-based allocations. Simple routing along the branches is used between these nodes. Withdrawals from the river or reservoir are specified as irrigation water users and/or regular water users (e.g. domestic or industrial). These capabilities make MIKE HYDRO well-suited not only for regional scale assessments of the impacts of climate change on regional water resources but also for subsequent assessment of regional scale climate adaptation options.

\section{Results}

The regional hydrological model has been developed and calibrated against available discharge data within the period 1960 to 1980 . This period of 21 years is assumed in this analysis to be representative of the variability for the reference period (1961-1990). The MIKE HYDRO model was then run using bias-corrected values for rainfall and PET over the same period. All other factors such as the operation and operation strategies of the reservoirs, the extractions for irrigation, etc. were kept fixed. The resulting changes are therefore solely because of projected changes in the climate.

Figure 4 presents the projected flows at the Jinja station for the two periods; near future (2020-2049) and far future (2070-2099). The Jinja station is located at the outlet of Lake Victoria. It is an important control point with the Owen Falls dam located just downstream. The releases follow the socalled "Agreed Curve" to provide releases that resemble the natural outflows from the lake prior to its construction. The outflow control is shown clearly in the flow duration curve for the low flows. One of the key features that determine the hydrology of the lake is the high contribution $(85 \%)$ of rainfall directly over the lake to total lake inflow. This direct precipitation suggests that lake levels and the long-term outflow will be highly sensitive to climatic change, as the water does not flow via the terrestrial water cycle (Williams et al., 2014). The flow projections indicate reductions in the flows for the near future (2020-2049) but with different magnitudes among the 5 ensemble members. For the far future (2070-2099), both increasing and decreasing trends are evident.

\section{Discussion}

A regional-scale modelling framework has been developed to address the need for regional scale tools and information that can support and inform decision-making for large transboundary river basins like the Nile. The framework incorporates the state of the art Perturbed Physics Ensemble (PPE) approach for climate change modelling and appropriate hydrological modelling using MIKE HYDRO. As a result, the framework can provide an assessment of climate change impacts, an indication of the uncertainties and can be used for regional scale adaptation. This framework can be readily applied to similar large or transboundary river basins in Africa and in other regions (Asia, South America) or used to at smaller scales to evaluate national or local climate impact assessments for water resources, water resource management and the evaluation of climate adaptation measures.

Acknowledgements. This study has been carried out by DHI and the UK Met Office in collaboration with NBI within the project "Adaptation to climate change induced water stress in the Nile River Basin". This project was launched in March 2010 as a 

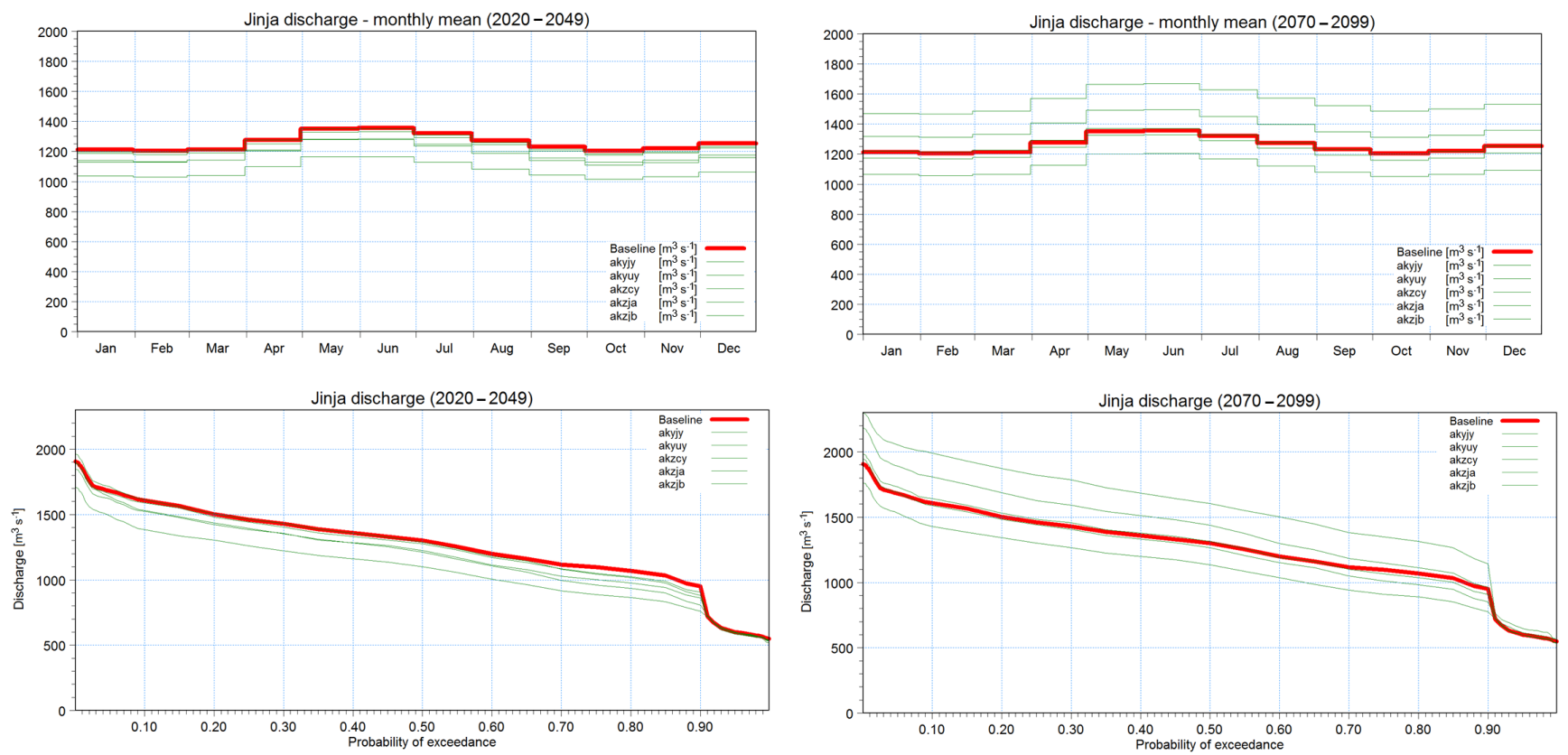

Figure 4. Projected changes in the average monthly flows (upper) and flow duration curve (lower) for 2020-2049 (left) and 2070-2099 (right) for the Jinja station. The solid (red) line shows the baseline levels (1961-1990) and the thin green lines show the variability among the 5 RCM ensemble members.

partnership between the United Nations Environment Programme UNEP and the Nile Basin Initiative (NBI), sponsored by the Swedish International Development Co-operation Agency (SIDA). This study was carried out under Project Co-operation Agreement (PCA/2010/DEPI/CCAU/005) between UNEP and DHI. The authors would also like to acknowledge the support of UNEP-DHI and their respective organisations.

\section{References}

Buontempo, C., Lørup, J. K., Sanderson, M., Butts, M., Palin, E., McCarthy, R., Jones, R., Betts, R., and Antar, M.: The impact of uncertainties in climate impacts assessments: the case of the Nile basin, in: Coping with Global Environmental Change: Climate Change, Soil and Desertification, Water Management, Food and Health, Hexagon Series on Human, Environmental Security and Peace (HESP), edited by: Brauch, H.-G., Spring, Ú. O., Mesjasz, C., Grin, J., Kameri-Mbote, P., Chourou, B., Dunay, P., and Birkmann, J., Berlin - Heidelberg - New York, Springer-Verlag, 5, 765-772, ISBN: 978-3-642-17775-0, doi:10.1007/s00382-0060121-0, 2011.

Buontempo, C., Mathison, C., Jones, R., Williams, K., Wang, C., and McSweeney, C.: An ensemble climate projection for Africa, Clim. Dynam., 44, 2097-2118, doi:10.1007/s00382-014-2286-2, 2015.

Butts, M. B., Payne, J. T., Kristensen, M., and Madsen, H.: An evaluation of the impact of model structure on hydrological modelling uncertainty for streamflow prediction, J. Hydrol., 298, 242-266, doi:10.1016/j.jhydrol.2004.03.042, 2004.

Butts, M. B., Dubicki, A., Stronska, K., Jørgensen, G., Nalberczynski, A., Lewandowski, A., and van Kalken, T.: Flood forecast- ing for the Upper and Middle Odra River Basin. Flood Risk Management in Europe: Innovation in Policy and Practice Series: Advances in Natural and Technological Hazards Research, edited by: Begum, S., Stive, M. J. F., and Hall, J. W., Vol. 25, Springer Science \& Business Media, ISBN: 1-4020-4199-3, doi:10.1007/978-1-4020-4200-3_19, 2007.

Collins, M. and Knight, S. K. (Eds.): Ensembles and probabilities: A new era in the prediction of climate change, Philos. T. R. Soc. A, 365, 1955-2191, ISSN: 1364-503X, 2007.

Collins, M., Booth, B. B. B., Harris, G. R., Murphy, J. M., Sexton, D. M. H., and Webb, M. J.: Towards quantifying uncertainty in transient climate change, Clim. Dynam., 27, 127-147, 2006.

Conway, D.: From headwater tributaries to international river: Observing and adapting to climate variability and climate change in the Nile Basin, Global Environ. Chan., 15, 99-114, doi:10.1016/j.gloenvcha.2005.01.003, 2005.

Conway, D., Hanson, C., Doherty, R., and Persechino, R.: GCM simulations of the Indian Ocean dipole influence on East African rainfall: present and future, Geophys. Res. Lett., 34, L03705, doi:10.1029/2006GL027597, 2007.

DHI: MIKE HYDRO User Manual, Hørsholm, Denmark, 2013.

Giorgi, F., Jones, C., and Asrar, G. R.: Addressing climate change needs at the regional level: the CORDEX framework, WMO Bulletin, 58, 175-183, 2009.

Harris, I., Jones, P. D., Osborn, T. J., and Lister, D. H.: Updated high-resolution grids of monthly climatic observations - the CRU TS3.10 Dataset, Int. J. Climatol., 34, 623-642, doi:10.1002/joc.3711, 2014.

Love, T. B., Kumar, V., Xie, P., and Thiaw, W.: A 20-year daily Africa precipitation climatology using satellite and gauge data, in: Proceedings of the 84th AMS Annual Meeting, P5.4. Conference on Applied Climatology, Seattle, WA, 2004. 
McSweeney, C. F., Jones, R. G., and Booth, B. B. B.: Selecting ensemble members to provide regional climate change information, J. Climate, 25, 7100-7121, doi:10.1175/JCLI-D-11$00526.1,2012$.

Palmer, T. N. and Williams, P. D.: Introduction. Stochastic physics and climate modelling, Philos. T. R. Soc. A, 366, 2421-2427, doi:10.1098/rsta.2008.0059, 2008.

SEDAC: Gridded Population of the World: Future Estimates. Socioeconomic Data and Applications Center (SEDAC); collaboration with CIESIN, UN-FAO, CIAT, Retrieved: $10 \mathrm{Au}-$ gust 2010, available at: http://sedac.ciesin.columbia.edu/data/ collection/gpw-v4, 2010.
UNEP: Africa Water Atlas, Division of Early Warning and Assessment (DEWA), United Nations Environment Programme (UNEP), Nairobi, Kenya, 2010.

Williams, K., Chamberlain, J., Buontempo, C., and Bain, C.: Regional climate model performance in the Lake Victoria basin, Clim. Dynam., 44, 1699-1713, doi:10.1007/s00382-014-2201-x, 2014. 